\title{
0088 INFLUENCE AND PROCESS OF PERCEIVED SCHOOL MULTICULTURALISM IN RELATION TO YOUTH DELINOUENCY AND DEPRESSION
}

T N Le, S Johansen*, J Wallen Correspondence: Department of Human Development and Family Studies, Colorado State University, 102 Gifford Building Campus, Delivery 1570502 West Lake St. Fort Collins, CO 80523, USA

\subsection{6/ip.2010.029215.88}

From a youth developmental perspective, multiculturalism entails the development of empathetic understanding, intercultural sensitivity, intercultural competence and civic mindfulness (Endicott, Bock \& Narvaez, 2003; Bennett, 1993; Cushner, 2008). While studies have examined multiculturalism with respect to academics (Chushner, 2008; Straffon 2003), few studies to date have explored the relation between perceived school multiculturalism and depression and delinquency. This study explores the relation between perceived school multiculturalism and two important youth outcomes, depression and delinquency. Potential mediators including civic engagement, ethno-cultural empathy, ethnic identity and positive peers were also explored as potential explanatory processes of this link.

Results Results revealed support for a full mediation model in which perceived school multiculturalism was positively associated with civic engagement, positive peers and ethnic identity; civic engagement and positive peers, in turn, were significantly negatively associated with delinquency but not depression. As recommended by Preacher and Hayes (2008), bootstrapping analyses were conducted to assess the effects of mediators by constructing confidence intervals around the estimates. The results portray that only civic engagement was a significant mediator between multiculturalism and delinquency.

Conclusions The results of this study reveal that there are potentially different pathways and mechanisms by which multiculturalism operates with respect to different youth outcomes. For delinquency, peer factors and sense of belonging seem to be more influential factors than the ability to tune in to the feelings and experiences of others, whereas such ability is more salient for the positive side of emotional health. 